\title{
PENGEMBANGAN SISTEM INFORMASI PENJAMINAN MUTU INTERNAL PADA FAKULTAS TEKNIK UNIVERSITAS MURIA KUDUS BERBASIS WEB
}

\author{
Yudie Irawan, Wiwit Agus Triyanto \\ ${ }^{1,2}$ Sistem Informasi Fakultas Teknik Universitas Muria Kudus \\ Email: ${ }^{1}$ yudie.irawan@umk.ac.id, ${ }^{2}$ wiwit.agus@umk.ac.id.
}

(Naskah masuk: 16 Desember 2020, diterima untuk diterbitkan: 31 Desember 2020)

\begin{abstract}
Abstrak
Penjaminan mutu berperan pada peningkatan kepastian dan kelengkapan dokumen mutu agar menjadi rencana pengembangan penjaminan mutu yang berjalan secara berkelanjutan. Penjaminan mutu di Fakultas Teknik telah berjalan dengan baik dan memiliki peran dalam menjaga dan meningkatkan kualitas mutu perguruan tinggi yang pelaksanaannya harus dikembangkan secara terus menerus. Namun dalam pelaksanaannya penjaminan mutu internal mengalami beberapa kendala antara lain kurangnya jumlah personil dan metode manual yang digunakan pada proses penyusunan laporan. Dua kendala tersebut berakibat pada lamanya proses monev pembelajaran dan pelaporannya. Disisi lain laporan - laporan penjaminan mutu dibutuhkan untuk kegiatan akreditasi yang idealnya tersedia secara rutin sesuai periode yang dilaporkan. Kendala lainnya adalah menumpuknya dokumen fisik yang tidak diimbangi dengan kapasitas penyimpanan yang memadai. Oleh karena itu perlu dikembangkan sistem informasi berbasis web yang mampu menjadi solusi untuk permasalahan tersebut, utamanya pada kegiatan monev pembelajaran dan pelaporannya. Metode pengembangan sistem yang digunakan adalah waterfall model dengan teknik perancangan unified modelling language. Dengan sistem ini diharapkan penggunaan dokumen fisik dapat dikurangi dengan adanya dokumen digital. Demikian juga diharapkan mampu mempercepat proses pelaporan monev pembelajaran secara periodik dengan baik dan menunjang dokumen akreditasi.
\end{abstract}

Kata kunci: monev pembelajaran, penjaminan mutu, , sistem informasi, Universitas Muria Kudus

\section{DEVELOPMENT OF A WEB-BASED INTERNAL QUALITY ASSURANCE INFORMATION SYSTEM AT THE FACULTY OF ENGINEERING, MURIA KUDUS UNIVERSITY}

\begin{abstract}
Quality assurance plays a role in increasing the certainty and completeness of quality documents so that it becomes a quality assurance development plan that runs continuously. Quality assurance at the Faculty of Engineering has been running well and has a role in maintaining and improving the quality of higher education, whose implementation must be developed continuously. However, in the implementation of internal quality assurance, there are several obstacles, including a lack of personnel and manual methods used in the report preparation process. These two obstacles resulted in the length of the monitoring and evaluation process for learning and reporting. On the other hand, quality assurance reports are needed for accreditation activities which should ideally be available on a regular basis according to the reported period. Another obstacle is the accumulation of physical documents which is not matched by adequate storage capacity. Therefore it is necessary to develop a web-based information system that can be a solution to these problems, especially in monitoring and evaluation activities and reporting. The system development method used is the waterfall model with the unified modeling language design technique. With this system, it is expected that the use of physical documents can be reduced by the presence of digital documents. Likewise, it is hoped that it will be able to accelerate the periodic monitoring and evaluation process of learning monitoring and evaluation and to support accreditation documents.
\end{abstract}

Keywords: monitoring and evaluation of learning, quality assurance, information systems, Muria Kudus University

1. PENDAHULUAN (huruf besar, 10pt, tebal)

Untuk mewujudkan pendidikan perguruan tinggi yang bermutu, Dikti telah mensyaratkan 
adanya penjaminan mutu (quality assurance) bagi seluruh Perguruan Tinggi melalui Sistem Penjaminan Mutu Pendidikan Tinggi (SPM Dikti). Sistem Penjaminan Mutu telah lama diumumkan pemerintah, yang dituangkan dalam Undang-undang No. 12 Tahun 2012 tentang Pendidikan Tinggi, yang menerangkan bahwa SPM Dikti ini meliputi Sistem Penjaminan Mutu Internal (SPMI) dan Sistem Penjaminan Mutu Eksternal (SPME) atau yang lebih dikenal dengan Akreditasi. Sehingga Sistem Penjaminan Mutu oleh Dikti meliputi sistem penjaminan mutu internal dan external.

Pelaksanaan Sistem Penjaminan Mutu di Fakultas Teknik secara rutin telah dilaksakan, salah satunya dalam bentuk Monitoring dan Evaluasi Pembelajaran, yang dilaksanakan pada awal semester dan akhir semester. Penjaminan mutu juga berorientasi pada peningkatan kepastian dan kelengkapan dokumen mutu agar menjadi rencana pengembangan penjaminan mutu yang berjalan secara berkelanjutan. Penjaminan mutu di Fakultas Teknik memiliki peran dalam menjaga dan meningkatkan kualitas mutu perguruan tinggi yang pelaksanaannya harus dikembangkan secara terus menerus demi memperoleh kualitas pergurutan tinggi yang mampu diandalkan oleh masyarakat. Ditemukan bahwa penyelenggaraan mutu pendidikan merupakan reaksi atas sejumlah perubahan keadaan yang terkait dengan: (a).perubahan konteks yang terkait dengan sebaran profil mahasiswa, internalisasi pendidikan tinggi maupun pasaran kerja. (b) munculnya angkatan kerja dan mahasiswa (c) ketidakpuasan dari pekerja dan mahasiswa (d) desakan karena terbatasnya dana (e) tuntutan untuk melakukan pertanggung jawaban terhadap kelembagaan (Safi'i \& Vidy, 2017).

Dalam pelaksanaannya penjaminan mutu internal mengalami beberapa kendala antara lain kurangnya jumlah personil dan metode manual yang digunakan pada proses penyusunan laporan. Dua kendala tersebut berakibat pada lamanya proses monev pembelajaran dan pelaporannya. Disisi lain laporan - laporan penjaminan mutu dibutuhkan untuk kegiatan akreditasi yang idealnya tersedia secara rutin sesuai periode yang dilaporkan. Kendala lainnya adalah menumpuknya dokumen fisik yang tidak diimbangi dengan kapasitas penyimpanan yang memadai, mengingat bahwa bukti - bukti yang berupa dokumen fisik akan bertambah pada setiap semester.

Berdasarkan hal tersebut diatas maka institusi, dalam hal ini Fakultas Teknik Muria Kudus membutuhkan sistem informasi yang mampu mengakomodasi berbagai kebutuhan dalam rangka lancarnya penjaminan mutu internal di tingkat fakultas, utamanya pada kegiatan monitoring dan evaluasi pembelajaran dan pelaporannya. Sistem yang mampu menjawab permasalahan tersebut adalah sistem informasi yang berjalan pada platform teknologi web, dimana sistem informasi berbasis web dapat diakses dimana dan kapan saja tanpa dibatasi oleh ruang dan waktu. Dengan sistem ini diharapkan penggunaan dokumen fisik dapat dikurangi dengan adanya dokumen digital. Demikian juga diharapkan mampu mempercepat proses pelaporan monev pembelajaran secara periodik dengan baik.

\section{METODOLOGI PENELITIAN}

Konsep yang diterapkan dalam tahap perancangan Sistem Informasi Penjaminan Mutu Internal adalah dengan menggunakan Rekayasa Perangkat Lunak model Waterfall. Rekayasa Perangkat Lunak ialah sebagai disiplin manajerial dan teknis yang berhubungan dengan penemuan sistematik, produksi dan maintenance sistem perangkat lunak yang berkualitas tinggi, disampaikan pada waktu yang tepat serta memiliki harga yang mahal(Ladjamudin, 2013).

Tahap-tahap dalam model waterfall tersebut antara lain:

a. Perencanaan sistem

1) Perencanaan Penelitian

Pada tahap ini dilakukan perencanaan sistem yang akan dibuat pada UPM Fakultas Teknik Universitas Muria Kudus. Perencanaan dibuat berdasarkan kebutuhan pengguna dalam melaksanakan kegiatan penjaminan mutu di tingkat fakultas. Pengguna yang dilibatkan antara lain pimpinan fakultas dan program studi, ketua dan anggota Unit Penjaminan Mutu Fakultas dan dosen di Fakultas Teknik Universitas Muria Kudus

2) Pengumpulan Data

Untuk mendapatkan data yang akurat maka dalam penelitian ini pengumpulan data dilakukan dengan cara :

a. Observasi

Pada tahap ini pengumpulan data melalui pengamatan dan pencatatan terhadap masalah yang ditemui. Permasalahan yang ditemui antara lain ;tingkat validitas data monev pembelajaran, banyaknya keterlambatan pengumpulan borang monev, pelaksanaan monev pembelajaran yang kurang efektif dan kesulitan pelacakan historis laporan.

b. Studi Pustaka

Pada tahap ini mencari teori yang dapat digunakan sebagai landasan teori / kerangka dalam penelitian seperti pedoman dalam penjaminan mutu, pedoman penyusunan beban kinerja dosen, jurnal penelitian mengenai sistem penjaminan mutu, untuk mencari metodologi yang sesuai dan membandingkan antara teori yang ada dengan fakta yang ada di lapangan

b. Analisa sistem

Pada tahap ini telah dilakukan analisa terhadap permasalahan yang ada. Kegiatan yang dilakukan adalah:

1) Mengidentifikasi kebutuhan informasi pengguna, antara lain informasi dosen, informasi 
mata kuliah, informasi pengampu mata kuliah, informasi kelas, informasi kesiapan materi perkuliahan, informasi bahan ajar dan informasi hasil pembelajaran.

2) Memberikan solusi alternatif sistem yang diusulkan. Mempertimbangkan waktu penelitian yang telah ditentukan, tidak semua kebutuhan pelanggan dapat diselesaikan dalam satu rentang waktu penelitian. Oleh karena itu timbul beberapa alternatif sistem informasi yang dapat mengakomodir kepentingan pengguna dan sistem yang memiliki fleksibilitas untuk pengembangan selanjutnya.

3) Pemilihan/kelayakan sistem. Yaitu memilih satu dari sekian solusi alternatif sistem yang ditawarkan. Dari beberapa alternatif yang akan dibangun, maka prioritas sistem penjaminan mutu fakultas yang dibangun adalah sistem monitoring dan evaluasi pembelajaran.

4) Pemodelan Objek. Pada bagian ini sistem akan dimodelkan menjadi objek dan kelas-kelas yang saling berhubungan.

c. Perancangan sistem

Pada tahap ini dilakukan penyusun sistem baru dan menerangkannya secara tertulis, kegiatan yang dilakukan adalah:

1) Perancangan diagram use case

2) Perancangan kebutuhan database dan tabel

3) Perancangan Kelas Antarmuka (Interface) Tampilan.

d. Pembuatan Program.

Proses pembuatan program adalah tahapan dimana hasil dari perancangan yang telah sesuai dengan kebutuhan pihak - pihak terkait di implementasikan ke dalam aplikasi melalui bahasa pemrograman.

e. Implementasi dan Testing

Penguijan dilakukan melalui alur kewenangan

Unit Pelaksana Teknis Pengembangan Sistem Informasi(UPT PSI), saat sistem telah diimplementasikan pada server UPT. PSI. Pengujian melibatkan user secara langsung, baik dari pihak dosen, pejabat struktural dan UPM. Proses pengujian menggunakan metode whitebox testing yang langsung dilakukan oleh programmer. Meningkat pada pengujan validasi dan pengujian sistem dengan metode blackbox. Pengujian blackbox dilakukan dengan teknik partisi ekuivalensi yang memilah data uji menjadi kelas - kelas

\section{HASIL DAN PEMBAHASAN}

Sistem informasi penjaminan mutu dapat berfungsi untuk memudahkan bagi perguruan tinggi dalam menjalankan penjaminan mutu, sehingga proses penjaminan mutu bisa dijalankan melalui tahap-tahap yang terangkai dan didukung oleh pangkalan data (basis data), sistem informasi manajemen, dan sistem pendukung keputusan yang terintegrasi.(Nuraeni, 2010). Alasan dipilihnya platform berbasis web adalah bahwa dosen telah terbiasa menggunakan platform ini, dapat diakse dari mana dan kapan saja. Web adalah salah satu aplikasi yang berisikan dokumen-dokumen multimedia (teks, gambar, animasi, video) didalamnya yang menggunakan protokol HTTP (Hypertext Transfer Protocol) dan untuk mengaksesnya menggunakan perangkat lunak yang disebut browser(Arief, 2011).

Perancangan pada penelitian ini menggunakan use case diagram untuk menggambarkan cara kerja user dengan sistem. Pada use case sistem diagram terdapat 6 aktor atau user yang berhubungan langsung dengan sistem dengan tingkat kewenangan yang berbeda - beda. User tersebut antara lain Administator Sistem, Dekan, Ka.Progdi, Tim Penjaminan Mutu, Unit Penjaminan Mutu dan Dosen.

Kewenangan Administrator Sistem meliputi Pengaturan Tahun Akademik, Aktifasi Borang, Input Master Dosen, Input Mata Kuliah, Input Program Studi, Input data Pengguna dan Input Data Aspek. Sedangkan akses yang dapat dilakukan oleh Tim Penjaminan Mutu yaitu Menginput Data Pengampu setiap mata kuliah. Setelah itu Dosen dapat mengisi borang monev pembelajaran sesuai mata kuliah yang diampu beserta kelasnya. Isi borang akan dievaluai oleh Unit Penjaminan Mutu setelah mendapatkan persetujuan secara digital oleh Ketua Program Studi. Hasil evaluasi monitoring dan evaluasi dapat dilihat oleh Unit Penjaminan Mutu dan Dekan.

Use case sistem dari Sistem Informasi Penjaminan Mutu Internal pada Fakultas Teknik Universitas Muria Kudus dapat dilihat pada gambar 1.

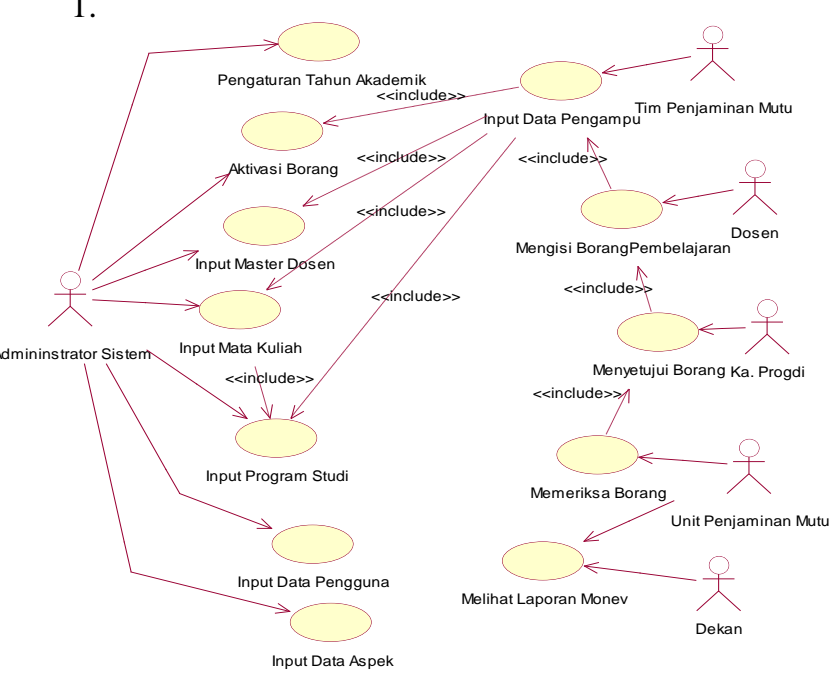

Gambar 1. Diagram Sistem Use Case Sistem Informasi Penjaminan Mutu Internal pada Fakultas Teknik Universitas Muria

Tahapan berikutnya yaitu perancangan database dengan hasil akhir Relasi Tabel yang dapat dilihat pada gambar 2 . 


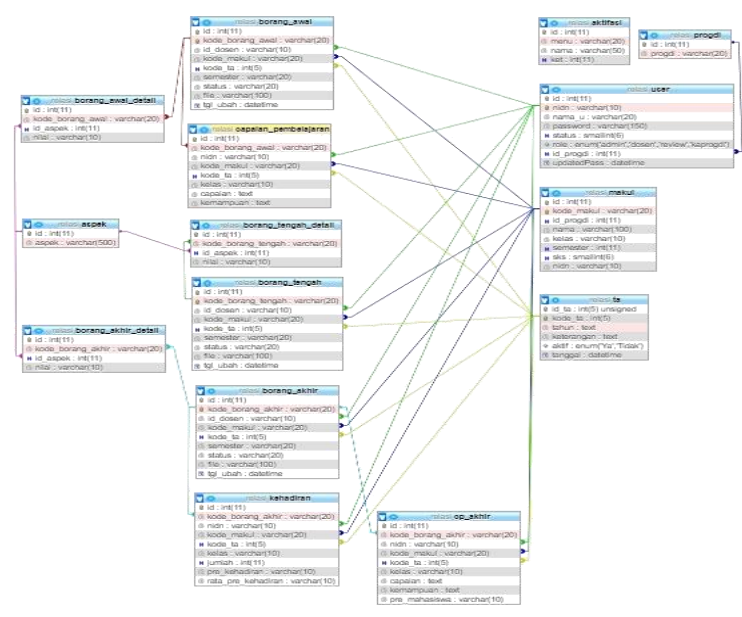

Gambar 2. Relasi Tabel pada Sistem Informasi Penjaminan Mutu Internal pada Fakultas Teknik Universitas Muria

Pada relasi tabel tersebut terdapat 15 tabel yang terdiri dari tabel berasal dari entitas sistem, dan tabel bantu yang berasal dari hasil relasi entitas. Tabel tabel tersebut antara lain adalah, borang_awal_detail(data rinci borang awal semester), aspek(Aspek pengisian borang), borang_akhir_detail(data rinci borang akhir semester), borang_awal(data utama borang awal semester), capaian_pembelajaran(data capaian pembelajaran, borang_tengah_detail(data rinci borang tengah semester), borang_tengah(data utama borang tengah), borang_akhir(data utama borang akhir semester), kehadiran(data kehadiran mahasiswa), op_akhir(tabel bantu borang akhir semester), user(data user), makul(data mata kuliah), ta(data tahun akademik),aktifasi(data aktifasi) dan progdi(data program studi).

Hasil implementasi dari perancangan sistem dan database yaitu berupa Sistem Informasi Penjamian Mutu Internal pada Fakultas Teknik Universitas Muria Kudus Berbasis Web yang dapat diakses melalui alamat http://borang.artaya.my.id/ .

Pada saat diakses, sistem akan menampilkan halaman login, yang berfungsi untuk mengidentifikasi user yang menggunakan akan menggunakan sistem. Halaman login dapat dilihat pada gambar 3 .

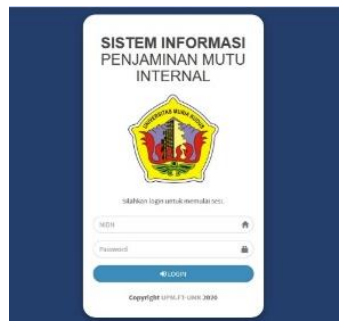

Gambar 3. Halaman login Sistem Informasi Penjaminan Mutu Internal Fakultas Teknik.

Fitur aktifasi borang dibutuhkan untuk melakukan pengaturan borang yang bisa diakses dan borang yang tidak bisa diakses. Misalkan pada waktu mengisi borang awal semester maka user tidak disediakan akses untuk mengisi borang tengah semester dan atau borang akhir semester. Halaman aktifasi borang dapat dilihat pada gambar 4 .

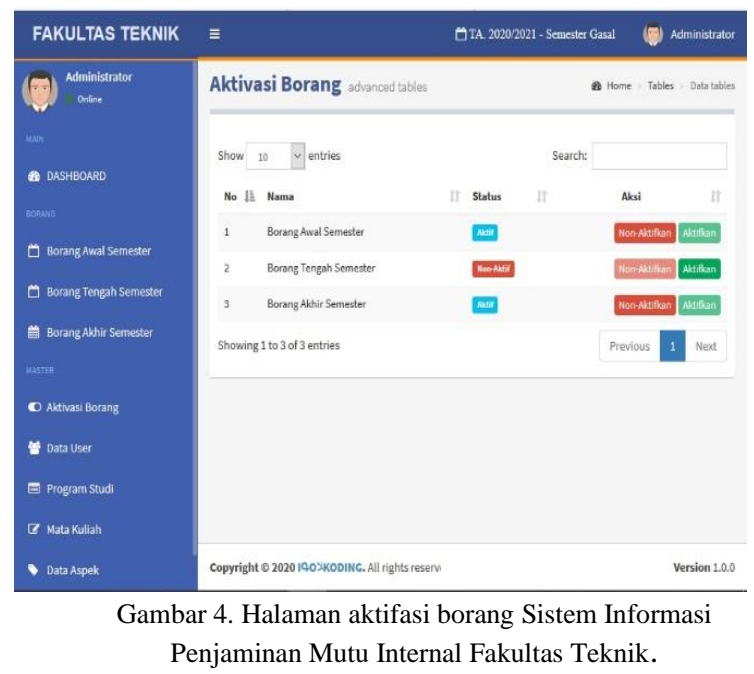

Fungsi utama dari Sistem Informasi Penjaminan Mutu Internal Fakultas Teknik adalah pengisian borang oleh dosen dan evaluasi oleh Unit Penjaminan Mutu. Halaman pengisian borang monev diambil dari versi manual borang monev pembelajaran. Terdapat pengunggahan rps, 15 aspek dan informasi capaian pembelajaran yang harus di isi oleh dosen untuk borang awal semester, sedangkan untuk borang tengah dan akhir semester terdapat 15 aspek dan capaian pembelajaran, persentase kehadiran mahasiswa dan persentase nilai mahasiswa dari tiap kelas. Halaman pengisian borang dapat dilihat pada gambar 5 .

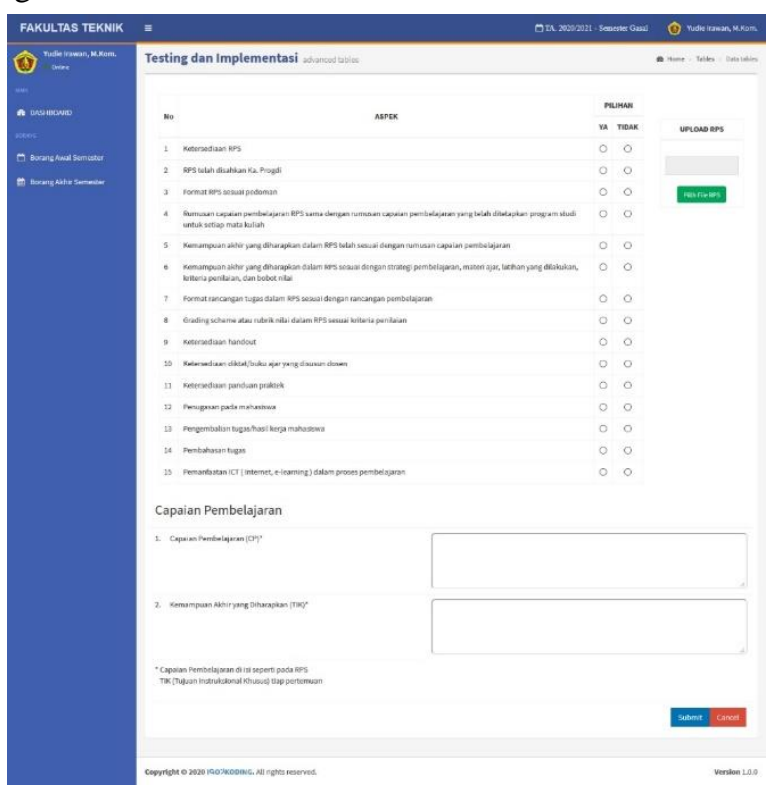

Gambar 5. Halaman pengisian borang, Sistem Informasi Penjaminan Mutu Internal Fakultas Teknik.

Pelaksanaan evaluasi dilakukan oleh Unit Penjaminan Mutu dengan membuka borang yang telah di isi oleh dosen. Pada kolom terakhir terdapat kolom untuk menandai terpenuhi atau tidaknya setiap 
aspek dan mengisi penilaian pada bagian bawah halaman. Halaman evaluasi monev pembelajaran dapat dilihat pada gambar 6 .

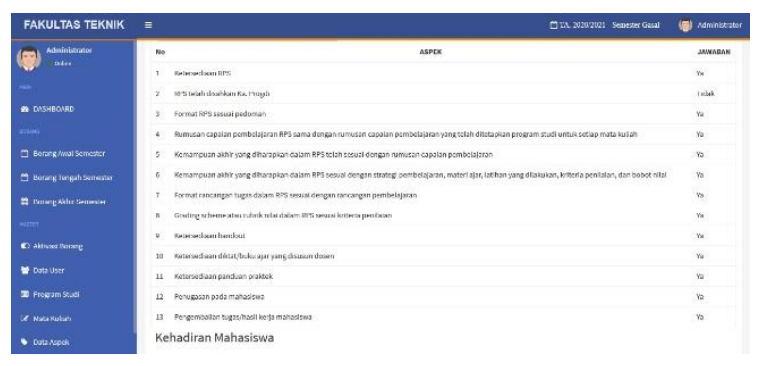

Gambar 6. Halaman monev pembelajaran Sistem Informasi Penjaminan Mutu Internal Fakultas Teknik

Tahap Pengujian Unit pada Sistem Informasi Penjaminan Mutu Internal menggunakan automation test Selenium IDE pada address aplikasi Sistem Informasi Penjaminan Mutu yaitu http://borang.artaya.my.id/. Hasil pengujian antara lain dapat dilihat pada gambar 7 .

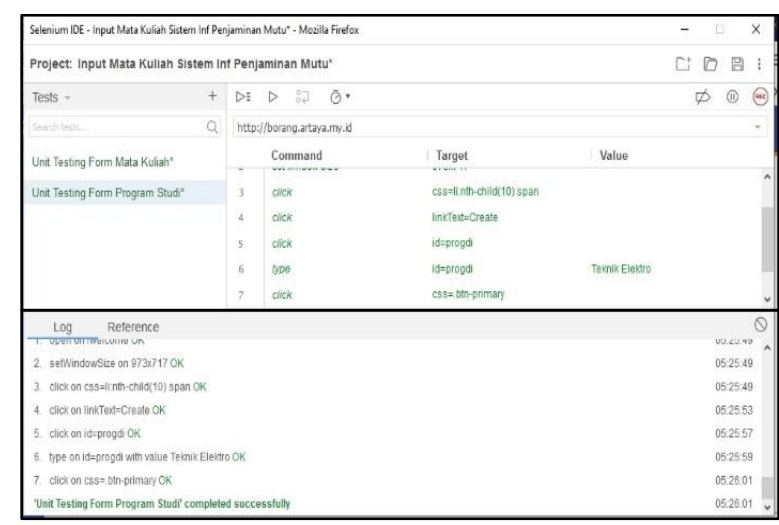

Gambar 7. Pengujian menggunakan Selenium IDE input mata kuliah pada Sistem Informasi Penjaminan Mutu Internal Fakultas Teknik

Pengujian form input data mata kuliah dilakukan dengan menginputkan data mata kuliah dengan mengkondisikan 1 alur data benar dan 2 alur data salah, hasil pengujian menunjukkan "completed succesfully"yang tampak pada baris kesimpulan pengujian Selenium IDE.

\section{KESIMPULAN}

Sistem Informasi Penjaminan Mutu Internal Fakultas Teknik Universitas Muria Kudus dikembangkan menggunakan metode pengembangan sistem waterfall dengan pemodelan use case system diagram. Pengujian sistem menggunakan teknik automation testing dengan perangkat testing Selenium IDE. Hasil pengujian menunjukkan bahwa sistem layak digunakan oleh pengguna.

Adapun kendala dalam pembuatan Sistem Informasi Penjaminan Mutu Internal Fakultas Teknik Universitas Muria Kudus adalah alokasi waktu yang cukup ketat untuk memenuhi semua kebutuhan pengguna, sehingga sistem harus melalui proses maintenance yang lebih lama.

\section{DAFTAR PUSTAKA}

ARIEF, M. R. (2011). Pemrograman Web Dinamis menggunakan PHP dan MySQL. Yogyakarta: CV. Andi Offset.

BAHAR. (2013). Analisa dan Design Sistem Informasi. Yogyakarta: Graha Ilmu.

DARMAWAN, A. (Sistem K. I. B. dan I. D. B. L., \& Hasibuan, M. S. (Sistem K. I. B. dan I. D. B. L. (2014). Analisis dan Perancangan Aplikasi Sistem Informasi Audit Mutu Internal dan Dokumentasi Penjaminan Mutu Perguruan Tinggi. Jurnal Generic, 9(2), 342-347.

LADJAMUDIN, A.-B. Bin. (2013). Analisis dan Desain Sistem Informasi. Yogyakarta: Graha Ilmu.

NURAENI, Y. (2010). Perancangan Sistem Informasi Penjaminan Mutu Perguruan Tinggi Bidang Sumber Daya Manusia. Journal of Information Systems, 6(1), 3243.

PRESSMAN, R. S., \& Maxim, B. (2014). Software Engineering, a Practitioner's Approach (8th ed.). New York: McGraw-Hill.

SAFI'I, M., \& Vidy. (2017). Perancangan Sistem Informasi Badan Penjaminan Mutu. Metik, 1(2), 1-7.

UBAIDILLAH, P. (Sistem I. I. B. dan I. S., Tjandrarini, A. B. (Sistem I. I. B. dan I. S., \& Amelia, T. (Sistem I. I. B. dan I. S. (2016). Rancang Bangun Aplikasi Pengelolaan Dokumen Sistem Penjaminan Mutu Internal Berbasis Web, ISSN 2338-137X. JSIKA, 5(2), 1-9. 